\title{
Can Both Low and High Self-esteem Be Related to Aggression in Children?
}

\author{
Sofia Diamantopoulou, Ann-Margret Rydell and Lisbeth Henricsson, \\ Uppsala University, Sweden
}

\begin{abstract}
This study examined the opposing hypotheses that either low or exaggerated but disputed self-esteem is related to aggression in 652 12-year-old schoolchildren. Children provided peer nominations of social acceptance and of physical aggression, self-ratings of global self-worth and of social satisfaction. Teachers rated aggressive behavior and internalizing problems. Exaggerated but disputed self-esteem was conceptualized as discrepancies between self and peer evaluations of social satisfaction and of social acceptance, respectively, in combination with peer rejection. The main results showed that both low levels of global self-worth and exaggerated but disputed self-esteem were related to aggression. The findings indicated that, depending on how self-esteem is conceptualized, aggressive children may appear to have both a low and a high self-esteem. Regarding gender differences, exaggerated self-esteem was more strongly related to aggression in boys than in girls.
\end{abstract}

Keywords: self-esteem; aggression; gender differences; children

\section{Introduction}

The relation between aggression and self-esteem in children has received renewed attention during the past decade and is currently debated. One view suggests that aggression and antisocial behavior in children are an expression of children's low self-esteem (low self-esteem hypothesis; Donnellan, Trzesniewski, Robins, Moffitt, \& Caspi, 2005; Fergusson \& Horwood, 2002; Gjerde, Block, \& Block, 1988). On the other side, researchers argue that aggression in children stems from a high self-esteem that is threatened or disputed by others (disputed self-esteem hypothesis; e.g., Baumeister, Bushman, \& Campbell, 2000; Baumeister, Smart, \& Boden, 1996; Bushman \& Baumeister, 1998; Hymel, Bowker, \& Woody, 1993). Given the theoretical attention surrounding this issue as well as its clinical implications, the present study was designed to further our understanding of the link between aggression and selfesteem in children. Specifically, we examined the relations between different psyk.uu.se 


\section{Sofia Diamantopoulou, Ann-Margret Rydell and Lisbeth Henricsson}

conceptualizations of self-esteem and aggression, also taking into account internalizing problems, peer relations, and gender differences.

How can both low and high self-esteem be related to aggression in children? We suggest two possible reasons. Firstly, the definition of 'high' and 'low' self-esteem has varied in different studies. Whereas a child's absolute levels of self-esteem can be 'high' or 'low' when compared to peers' self-esteem, a child's self-esteem can also be 'high' or 'low' relative to observers' (e.g., peers') ratings of the child's behavior and competencies. The latter definition refers to a child's overestimations or underestimations of behavior and competencies relative to observers' ratings.

Secondly, the conceptualization of self-esteem has varied in the literature. Selfesteem has been conceptualized either as global self-evaluations reflecting how satisfied one is with how one is leading one's life, or as domain-specific evaluations of behavior or competence (Harter, 1988). Studies providing support for the low selfesteem hypothesis have examined absolute levels of global self-esteem (Donnellan et al., 2005; Fergusson \& Horwood, 2002), whereas studies providing support for the disputed self-esteem hypothesis have examined overestimations of social acceptance, that is, overestimations of domain-specific evaluations of competence (e.g., Rudolph \& Clark, 2001; Van Boxtel, Orobio de Castro, \& Goossens, 2004). Hence, depending on whether absolute levels of global self-evaluations or relative evaluations of social acceptance have been examined, both low and high levels of self-esteem have been related to aggression in children. To date, no studies have examined in the same sample the relations between aggression and different definitions of 'high' and 'low' levels of self-esteem conceptualized as absolute or relative levels of self-evaluations.

Why should low global self-esteem be related to aggression? Firstly, low global self-esteem has been found to correlate highly with depression (for a review, see Harter, 1999) and it may be viewed as a reflection of children's internalizing problems. It has been suggested that aggression and depression may be linked to each other due to the more overall relation between externalizing and internalizing problems in children (Weiss \& Catron, 1994; Weiss, Süsser, \& Catron, 1998). However, previous studies supporting the notion that low self-esteem is related to aggression (Donnellan et al., 2005; Fergusson \& Horwood, 2002) have not controlled for effects of internalizing problems.

Secondly, low global self-esteem may be a reflection of children's poor peer relations. Contemporary developmental theories suggest that children's self-esteem emerges from an internalization of the views of significant others (Cole, Maxwell, Martin, Peeke, \& Seroczynski, 2001; Harter, 1999). As children enter middle childhood (i.e., around the age of seven), the peer group plays an increasingly large role in influencing children's cognitions and behavior, and the influence of peer approval is therefore critical during this time (Harris, 1995; Patterson, Kupersmidt, \& Griesler, 1990; Rudolph, Caldwell, \& Conley, 2005). Negative peer experiences such as peer rejection have been associated with both unfavorable views of the self and with aggression (Cassidy \& Asher, 1992; Guerra, Asher, \& DeRosier, 2004; Ladd \& Troop-Gordon, 2003). Although low global self-esteem has been related to aggression even after control for self-ratings of poor peer relations (Donnellan et al., 2005), the effects of actual peer rejection on the relation between self-esteem and aggression remain to be examined.

However, according to the disputed self-esteem hypothesis, children make an active choice as to whether they accept or reject peers' appraisals of their own behavior and competencies. Hence, if children's high self-evaluations of behavior and competencies are not concordant with peers' evaluations, children may act aggressively toward those 
who dispute their high evaluations (Baumeister et al., 1996, 2000). If, for instance, children hold a high self-esteem regarding their social acceptance despite actual peer rejection, to maintain their high self-evaluations they may choose to behave aggressively toward those who dispute them. Conversely, aggression and peer rejection are expected to interact in predicting overestimations of social acceptance. Aggressiverejected children are expected to overestimate their social acceptance more than nonaggressive children who are not rejected by peers or rejected non-aggressive children.

In line with the disputed self-esteem hypothesis, aggressive-unpopular or aggressive-rejected children have been found to overestimate their social acceptance more than non-aggressive average children, aggressive-accepted children, and rejected-non aggressive children (Hymel et al., 1993; Rudolph \& Clark, 2001; Zakriski $\&$ Coie, 1996). Furthermore, only among rejected children have overestimations of social acceptance been related to aggression (Van Boxtel et al., 2004). However, in this latter study, rejected children were compared with children differing in levels of aggression and sociability as comparison children belonged to all other peer status groups (e.g., popular, neglected). This complicates matters as, for instance, both popular and average children have been found to differ from rejected children in levels of aggression and sociability (for a meta-analytic review, see Newcomb, Bukowski, \& Pattee, 1993). In addition, although peer rejection and overestimations of social acceptance interacted in predicting aggression, this interaction was not interpreted. Hence, whether rejected children who overestimate their social acceptance behave more aggressively than average children who also overestimate their social acceptance remains to be examined.

In sum, two contradicting hypotheses regarding the link between self-esteem and aggression in children have been proposed. The low self-esteem hypothesis proposes that low global self-esteem is related to children's acts of aggression and antisocial behavior. The disputed self-esteem hypothesis proposes that exaggerated, in relation to observers' ratings, self-esteem regarding social acceptance, is related to children's acts of aggression only when children's exaggerated self-esteem is disputed by others (e.g., as in the case of peer rejection). Previous findings report contradicting results regarding the relations between self-esteem and aggression possibly due to different measurements of self-esteem levels (i.e., high/low self-esteem in comparison to peers' self-esteem vs. overestimations of competencies compared to peer ratings), or due to different conceptualizations of self-esteem (i.e., global self-evaluations vs. selfevaluations of social acceptance).

\section{This Study}

This study aimed to disentangle conflicting findings concerning the relation between self-esteem and children's acts of aggression measured by teacher ratings and peer nominations, incorporating several novel aspects: Firstly, we examined the relation between aggression and different conceptualizations of self-esteem previously used in the literature but never investigated in the same study, thus combining two views on self-esteem holding sample characteristics constant. We conceptualized self-esteem as global self-worth, and also, as discrepancies between self-ratings of social acceptance and social acceptance measured by peer nominations (i.e., discrepancy scores where positive values indicated overestimations of social acceptance). Secondly, to examine whether the association between low self-esteem and aggression is a reflection of the relation between internalizing and externalizing problems or of children's poor peer 


\section{Sofia Diamantopoulou, Ann-Margret Rydell and Lisbeth Henricsson}

relations, we controlled for the effects of internalizing problems and of peer acceptance when examining the relation between low global self-esteem and aggression. Thirdly, previous studies report that boys in general are more physically aggressive than girls (e.g., Coie \& Dodge, 1983; Maughan, Rowe, Messer, Goodman, \& Meltzer, 2004; Scourfield, John, Martin, \& McGuffin, 2004), and therefore we also examined gender differences in all the above relations.

To provide support for the low self-esteem hypothesis, low levels of global selfworth should be associated with high levels of peer and teacher evaluations of aggression. In case global self-worth was a reflection of children's internalizing problems or negative peer relations, we expected that global self-worth would not predict aggression after control for internalizing problems and for peer rejection. To provide support for the disputed self-esteem hypothesis, discrepancy scores should be positively related to peer and teacher evaluations of aggression for rejected children only. In the absence of previous findings regarding interaction effects of gender and self-esteem and interaction effects of gender, peer rejection, and overestimations of social acceptance on aggression, these analyses were exploratory.

We wanted to overcome some methodological limitations of previous research regarding the link between overestimations of social acceptance and aggression in children. To assess discrepancy scores, we used the standardized difference-and not the residual difference scores - between informants' ratings as used in previous studies (e.g., Van Boxtel et al., 2004). It has been shown that when subjective ratings are used and no informant can be viewed as the 'gold standard' by which another informant's ratings can be interpreted as representing absolute overestimations or underestimations, it is preferable to use the standardized difference between informants' ratings (De Los Reyes \& Kazdin, 2004). Finally, we examined the disputed self-esteem hypothesis, that is, the effects of peer rejection on the relation between overestimations of social acceptance and aggression, by comparing rejected children with children of average peer status. Excluding children of popular, neglected, and controversial peer status in these analyses made results easier to interpret as children of these different peer status groups have been found to differ in levels of aggression and sociability.

\section{Method}

As the recruitment of the sample, the procedure, and all the measures used have been described in detail in previous publications (see Diamantopoulou, Henricsson, \& Rydell, 2005; Henricsson \& Rydell, 2006) they are only presented briefly here.

\section{Participants and Procedure}

Participants were 652 twelve-year-old children $(M=12$ years and one month, $S D=4$ months; 330 boys) recruited from 30 classrooms in 23 elementary schools in a midsized Swedish university town. After consent from parents, we collected teacher ratings, self-reports, and sociometric nominations during the spring semester of grade six. Children of this age were selected because after the age of 9 to 10 , peer social status and especially rejected status, appears to be relatively stable (Coie \& Dodge, 1983). Children were informed that participation was voluntary and that all data were strictly confidential. 


\section{Measures}

Independent Variables. Peer relations. We used sociometric nomination questionnaires to examine children's peer relations in accordance with the standard method described by Ladd (1999). For all the measures of social functioning derived by peer nominations, we standardized items across gender within each class. Children were asked to nominate up to three children in the class that they liked and disliked the most. We derived a social preference score (SPS) by subtracting the number of nominations on the social disliking item from the number of nominations on the social liking item. Thus, children who received many negative nominations had either a low SPS or a negative one. We also derived a social impact score (SIS) score by summing the positive and negative nominations. We used SPS and SIS to compose the measurement of peer status and we also used SPS to compute the discrepancy scores (see further below).

To assess peer rejection we composed a measurement of peer status based on children's answers on the sociometric nominations questionnaire and divided children into peer status groups according to the Coie and Dodge (1983) procedure. In the analyses regarding the effects of peer rejection on the link between overestimations of social acceptance and aggression (see Statistical analyses) we compared the rejected $(\mathrm{N}=128)$ with the average $(\mathrm{N}=203)$ children, excluding children in the popular, neglected, and controversial peer status groups.

Global self-worth. To assess children's global self-evaluations we used a revised, Swedish version of Harter's self-perception profile for adolescents (SPPA; Harter, 1988). The revised version of the SPPA does not include the original format of the items that describe two children with opposite characteristics on each item. Instead, children made ratings on a 4-point scale with ascending numbers indicating more positive self-perceptions (scale range: $1=$ does not apply at all; $2=$ does not apply very well; 3 = applies quite well; $4=$ applies very well). Both positive and negative statements of self-perceptions were used, as in the original format of the SPPA, to minimize social desirability effects. The revised version has previously been administrated to a Scandinavian sample, where the factorial design of the original instrument was replicated, and reliability, convergent validity, and discriminant validity were the same or better than for the original version of the instrument (Wichstrøm, 1995). Children rated their global self-worth on the five items of the scale (e.g., 'I am happy with myself most of the time'; 'I like the person I am'; $\alpha=.82$ ).

Discrepancy scores. To assess overestimations of social acceptance we calculated discrepancy scores based on peer nominations of children's actual peer acceptance (i.e., SPS, see above) and children's self-perceptions of social satisfaction. We measured children's social satisfaction with 16 reversed items from the 'loneliness and social dissatisfaction questionnaire for young children' (e.g., 'It is easy for me to make new friends at school'—reversed, 'I feel alone at school' - reversed; Cassidy \& Asher, 1992). The response format was from $1=$ does not apply at all, to $4=$ applies very well; $\alpha=.87$. We calculated discrepancy scores between children's social satisfaction and peer nominations of children's social acceptance, that is, the SPS. As recommended by De Los Reyes and Kazdin (2004) discrepancy scores were based on the difference between children's and peers' standardized ratings of social satisfaction and of peer acceptance, respectively (for rejected and average peer status groups only). Positive values equaled overestimations of social acceptance relative to peer nominations, whereas negative values equaled underestimations. 


\section{Sofia Diamantopoulou, Ann-Margret Rydell and Lisbeth Henricsson}

Internalizing problems. We used internalizing problems only as a control variable. Teachers rated internalizing problems on five items from the child behavior questionnaire (e.g., 'Often worried', 'Often appears miserable'; Rutter, Tizard, \& Whitmore, 1970). Ratings ranged from $1=$ does not apply at all, to $5=$ applies very well; $\alpha=.79$. We used the mean score of items as a measure of internalizing problems.

Dependent Variables. Peer nominations of physical aggression. In the sociometric nominations (see above), peers nominated 'three children in the class who get into fights with others', and 'three children in the class who kick, push, and hit other children'; $\alpha=.81$. We chose to collect peer nominations on these two aggressive behaviors as they are the most frequently used in the literature (Ladd, 1999), and by limiting the number of nominations to three, which is the common procedure in sociometrics, we tried to ascertain that the most typically aggressive children would be nominated.

Teacher ratings of aggressive behavior. Teachers rated aggressive behavior on four items of the child behavior questionnaire (e.g., 'Frequently fights with other children'; 'Irritable, is quick to fly off the handle'; Rutter et al., 1970). Ratings ranged from $1=$ does not apply at all, to $5=$ applies very well; $\alpha=0.87$ ).

\section{Statistical Analyses}

In the preliminary analyses we conducted two-tailed $t$-tests to examine gender differences in all study variables for all children and calculated Pearson product moment correlations between all variables.

In the main analyses, to examine the relation between self-esteem and aggression, we conducted two hierarchical regression analyses. For both analyses, dependent variables were peer nominations of physical aggression and teacher ratings of aggressive behavior. We centered all the predictor variables (for the whole sample and for the rejected and average peer status groups for the first and second hierarchical regression analysis, respectively) before entering them into the analyses. We multiplied the centered predictors to obtain interaction terms. In case of a significant interaction effect we followed the procedure described by Aiken and West (1991) to interpret results.

In the first analysis (Model 1) we aimed to examine whether global self-worth would significantly predict aggression after control for gender, internalizing problems, and peer acceptance, and also, whether we would obtain gender differences in the relation between global self-worth and aggression. Hence, predictors were gender, internalizing problems, and the SPS in the first step, global self-worth in the second step, and the two-way interaction between gender and global self-worth in the third step. The first analysis was based on the total sample of the 652 children.

In the second analysis (Model 2) we aimed to examine whether discrepancy scores would predict aggression for the rejected children only and whether we would obtain gender differences in the relation between overestimations of social acceptance, peer rejection, and aggression. Therefore, only the rejected and average children were included in this analysis (331 children). We entered in the first step gender and peer status (dummy coded as 0 for rejected and 1 for average peer status group) as predictor variables. In the second step we entered discrepancy scores as predictor variables. In the third step we entered as predictor variables the two-way interaction term of either, (1) discrepancy scores and peer status, or (2) gender and discrepancy scores, or (3) gender and peer status. In the final fourth step we entered the three-way interaction of gender, peer status, and discrepancy scores as a predictor variable. 
Table 1. Descriptive Data for All Study Variables for Girls $(\mathrm{N}=322)$ and Boys ( $\mathbf{N}=330)$ and Gender Comparisons

\begin{tabular}{|c|c|c|c|c|}
\hline & \multicolumn{2}{|c|}{$M(S D)$} & \multirow[b]{2}{*}{$t$} & \multirow[b]{2}{*}{$d$} \\
\hline & Girls & Boys & & \\
\hline \multicolumn{5}{|l|}{ Self-ratings } \\
\hline Social satisfaction ${ }^{\dagger}$ & $3.41(.37)$ & $3.35(.41)$ & -1.97 & .15 \\
\hline Global self-worth & $3.34(.59)$ & $3.48(.51)$ & $3.18 * *$ & .25 \\
\hline \multicolumn{5}{|l|}{ Peer nominations } \\
\hline Physical aggression & $-.24(.46)$ & $.24(1.11)$ & $7.40 * *$ & .56 \\
\hline Social preference score ${ }^{\dagger}$ & $.00(.95)$ & $.00(1.00)$ & .98 & .00 \\
\hline \multicolumn{5}{|l|}{ Teacher ratings } \\
\hline Aggressive behavior & $1.37(.67)$ & $1.87(1.01)$ & $7.40 * *$ & .58 \\
\hline Internalizing problems & $1.61(.73)$ & $1.79(.87)$ & $2.84 * *$ & .22 \\
\hline Discrepancy scores & $.08(1.08)$ & $-.07(1.23)$ & 1.77 & .13 \\
\hline
\end{tabular}

${ }^{\dagger}$ Social satisfaction and social preference score were used to derive the discrepancy scores. $* * p<.01$.

\section{Results}

\section{Preliminary Analyses}

Descriptive statistics for all study variables and results of gender comparisons are shown in Table 1. Results of the preliminary analyses indicated that boys compared to girls were perceived by peers as being more physically aggressive. According to teacher ratings, boys compared to girls behaved more aggressively and displayed higher levels of internalizing problems. Girls reported lower levels of global self-worth than boys did, but we obtained no gender differences in discrepancy scores. Boys and girls did not differ in peer status classification; $\chi^{2}(4,651)=2.11$, NS.

In Table 2, correlations between all variables are presented. The correlation between teacher and peer assessments of aggression was substantial, indicating that aggression ratings from these two sources of information are fairly reliable. Further, the two aggression variables and internalizing problems were significantly positively related.

\section{Main Analyses}

To provide support for the low self-esteem hypothesis we expected low levels of global self-worth to be related to high levels of aggression. To provide support for the disputed self-esteem hypothesis we expected that, for rejected children only, high levels of overestimations of social acceptance would be related to high levels of aggression. As shown in Table 2, the bivariate correlations revealed, in line with the low self-esteem hypothesis, that global self-worth was weakly and negatively related to peer nominations of aggression and to teacher ratings of aggressive behavior. Discrepancy scores were positively related to peer nominations of physical aggression and to teacher ratings of aggression. 
Table 2. Correlations between Study Variables for All Children $(\mathrm{N}=652)$

\begin{tabular}{|c|c|c|c|c|c|c|c|}
\hline & 1 & 2 & 3 & 4 & 5 & 6 & 7 \\
\hline 1. Social satisfaction & - & $.39 * *$ & -.04 & $.34 * *$ & -.03 & $-.30 * *$ & $.58 * *$ \\
\hline 2. Global self-worth & & - & $-.10 * *$ & $.19 * *$ & $-.11 * *$ & $-.15 * *$ & $.18 * *$ \\
\hline $\begin{array}{l}\text { 3. Peer nominations } \\
\text { of physical } \\
\text { aggression }\end{array}$ & & & - & $-.38 * *$ & $.63 * *$ & $.08 *$ & $.30 * *$ \\
\hline 4. SPS & & & & 一 & $-.25 * *$ & $-.35 * *$ & $-.57 * *$ \\
\hline $\begin{array}{l}\text { 5. Teacher ratings of } \\
\text { aggressive behavior }\end{array}$ & & & & & - & $.28 * *$ & $.19 * *$ \\
\hline $\begin{array}{l}\text { 6. Internalizing } \\
\text { problems }\end{array}$ & & & & & & - & .04 \\
\hline 7. Discrepancy scores & & & & & & & - \\
\hline
\end{tabular}

$* p<.05, * * p<.01$.

SPS $=$ social preference score.

In terms of predicting aggression from self-esteem, results of the first hierarchical regression analysis (see Table 3, Model 1) showed that global self-worth independently predicted both variables of aggression even after control for the effects of gender, of internalizing problems, and of social acceptance. However, global self-worth explained the variance of the two aggression variables only to a small extent. All independent variables made significant independent contributions to the explained variance of both peer nominations of physical aggression and of teacher ratings of aggressive behavior.

Curiously, high levels of internalizing problems predicted high levels of teacher ratings of aggressive behavior but low levels of peer nominations of physical aggression, although, as mentioned above, internalizing problems correlated positively with both the aggression variables (see Table 2). This discrepancy between bivariate and multivariate analyses indicates the working of at least one suppressor variable, that is, variables that enhance the effect of other variables by suppressing variance that is irrelevant to the prediction of the outcome variable (Tabachnik \& Fidell, 2001). We followed the procedure described by Cohen and Cohen (1983) and identified two suppressor variables, namely gender and SPS. Thus, although not primarily a focus of this study, this analysis demonstrated a negative relation between internalizing problems and peer nominations of physical aggression when the effects of gender and peer acceptance were statistically controlled for.

Results of the second hierarchical regression analysis (see Table 3, Model 2) showed that discrepancy scores independently predicted both aggression variables after control for effects of gender and of peer status. Further, as predicted according to the disputed self-esteem hypothesis, we obtained two interaction effects between discrepancy scores and peer rejection regarding peer nominations of physical aggression and teacher ratings of aggressive behavior. It should however be noted that in both cases the interaction between discrepancy scores and peer rejection explained a small portion of variance of the two aggression variables. The interaction effects are illustrated in Figures 1 and 2. To interpret the interactions we plotted simple regression lines of overestimations of social acceptance on peer nominations of physical aggression and 
Table 3. Summary of Hierarchical Regression Analyses Predicting Peer Nominations of Physical Aggression and Teacher Ratings of Aggressive Behavior

\begin{tabular}{|c|c|c|c|c|}
\hline & \multicolumn{2}{|c|}{$\begin{array}{l}\text { Peer nominations } \\
\text { of physical } \\
\text { aggression }\end{array}$} & \multicolumn{2}{|c|}{$\begin{array}{c}\text { Teacher ratings } \\
\text { of aggressive } \\
\text { behavior }\end{array}$} \\
\hline & $\Delta R^{2}$ & $\beta$ & $\Delta R^{2}$ & $\beta$ \\
\hline \multicolumn{5}{|l|}{ Model 1} \\
\hline Step 1 & $.23 * *$ & & $.17 * *$ & \\
\hline Gender & & $-.29 * *$ & & $-.26 * *$ \\
\hline Internalizing problems & & $-.10 * *$ & & $.19 * *$ \\
\hline SPS & & $-.42 * *$ & & $-.18 * *$ \\
\hline \multicolumn{5}{|l|}{ Step 2} \\
\hline Global self-worth & & $-.07 *$ & & $-.08 *$ \\
\hline \multicolumn{5}{|l|}{ Step 3} \\
\hline Gender $\times$ global self-worth & .00 & .06 & .00 & .05 \\
\hline \multicolumn{5}{|l|}{ Model 2} \\
\hline Step 1 & $.22 * *$ & & $.16^{* *}$ & \\
\hline Gender & & $-.33 * *$ & & $-.31 * *$ \\
\hline Peer status & & $-.17 * *$ & & $-.08 *$ \\
\hline \multicolumn{5}{|l|}{ Step 2} \\
\hline Discrepancy score & & $.22 * *$ & & $.22 *$ \\
\hline \multicolumn{5}{|l|}{ Step 3} \\
\hline 2a. Discrepancy score $\times$ peer status & $.01 *$ & $-.12 *$ & $.01 *$ & $-.11 *$ \\
\hline 2b. Gender $\times$ discrepancy score & $.01 *$ & $-.10 *$ & .00 & .04 \\
\hline 2c. Gender $\times$ peer status & $.01 *$ & $.12 *$ & .00 & -.03 \\
\hline \multicolumn{5}{|l|}{ Step 4} \\
\hline $\begin{array}{l}\text { Gender } \times \text { peer status } \times \text { discrepancy } \\
\text { score }\end{array}$ & .00 & .09 & .00 & .07 \\
\hline
\end{tabular}

$* p<.05, * * p<.01$.

SPS $=$ social preference score; Peer status $=$ rejected and average peer status.

on teacher ratings of aggressive behavior, separately for rejected and average children controlling for gender. For rejected children, overestimations of social acceptance significantly predicted aggression, $\beta=.30, p<.01, t=3.93, p<.01$, and $\beta=.31$, $p<.01, t=3.70, p<.01$, for peer nominations of physical aggression and for teacher ratings of aggressive behavior, respectively. For children of average peer status, no effect of overestimations of social acceptance was found either for peer or teacher evaluations of aggression, .06 $\leq \beta \mathrm{s} \leq .07$, NS. Hence, children who overestimated their social acceptance and whose social acceptance was disputed by peers (i.e., they were rejected by peers) were rated as more aggressive than rejected and average children who did not overestimate their social acceptance and average children who overestimated their social acceptance.

In sum, comparison of the two regression analyses indicated that both models explained equal portions of variance in peer and teacher ratings of aggression. The 
10 Sofia Diamantopoulou, Ann-Margret Rydell and Lisbeth Henricsson

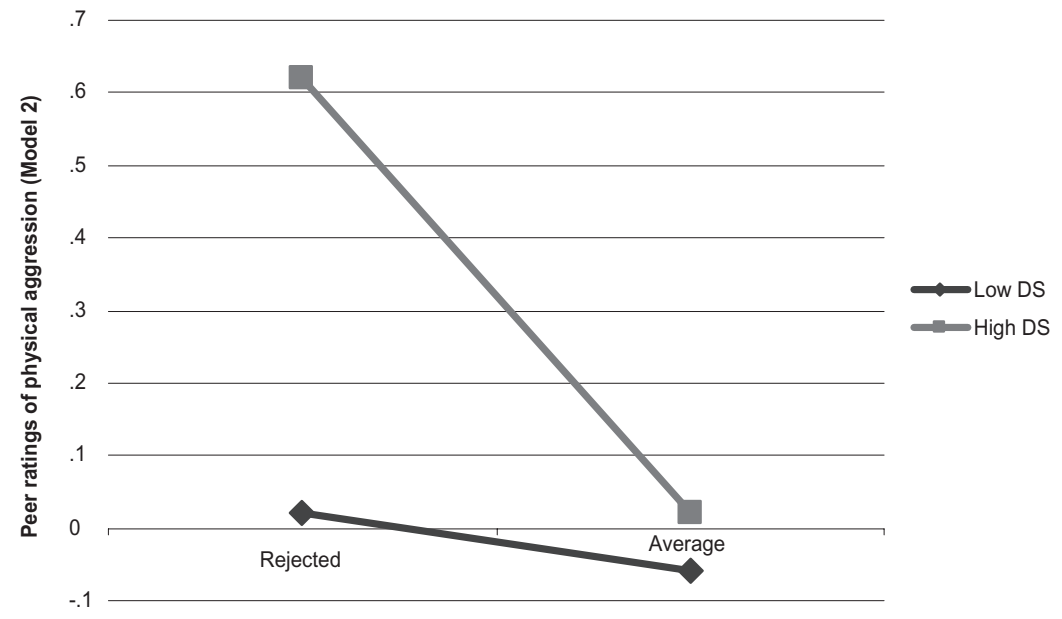

Figure 1. Illustration of Interaction Effects between Discrepancy Scores (DS) and Peer Status on Peer Nominations of Physical Aggression (Model 2).

2.5

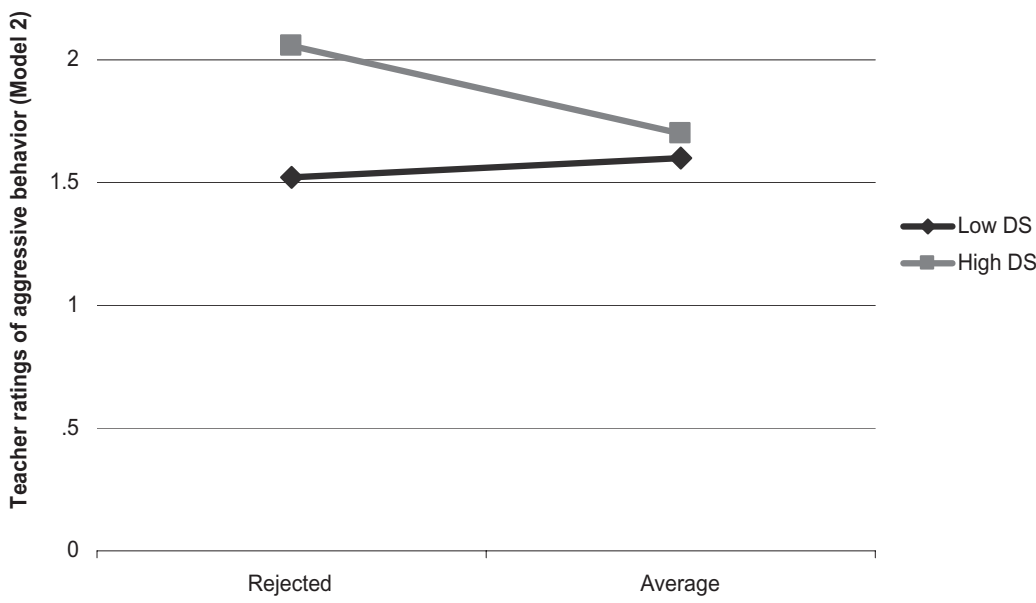

Figure 2. Illustration of Interaction Effects between Discrepancy Scores (DS) and Peer Status on Teacher Ratings of Aggressive Behavior (Model 2).

findings supported the low self-esteem hypothesis but global self-worth did not contribute much to the explained variance of the two aggression variables. The findings also supported the disputed self-esteem hypothesis as among children who overestimated their social acceptance, rejected children were perceived by both teachers and peers as being more aggressive than average children. However, there was also a general effect of overestimations of social acceptance as overestimations significantly predicted teacher and peer evaluations of aggression even after control for gender and peer status. This raised the question of whether low global self-worth and 
overestimations of social acceptance would give independent contributions and whether they would interact in the prediction of aggression. Thus, we conducted an additional hierarchical regression analysis on the whole sample. The two control variables, gender and internalizing problems (social acceptance was not used as a control variable because it served as one term in the overestimation variable), were entered in a first step together with global self-worth and overestimations of social acceptance. The interaction term between global self-worth and overestimations was entered in a second step. We centered all the predictor variables before entering them into the analysis. The findings revealed that low global self-worth significantly predicted peer nominations of physical aggression $(\beta=-.13, p<.05)$ and teacher ratings of aggressive behavior $(\beta=-.14, p<.05)$, as did overestimations of social acceptance ( $\beta=.40, p<.01$, and $\beta=.26, p<.01$, respectively for peer nominations of physical aggression and teacher ratings of aggressive behavior). The $\beta$ estimates indicated that overestimations of social acceptance seemed to have a larger effect on predicting the two aggression variables compared to low global self-worth. The two-way interaction effect between global self-worth and overestimations of social acceptance did not contribute in predicting the two aggression variables $(\beta \mathrm{s} \leq-.07, \mathrm{NS})$.

\section{Gender Differences}

As indicated by the results of the two hierarchical regression analyses (see Table 2), gender independently predicted the two aggression variables in both models.

Results of the first analysis (Model 1) indicated no gender differences in the relation between global self-worth and aggression as we obtained no interaction effect between gender and global self-worth regarding peer and teacher evaluations of aggression.

Results of the second hierarchical regression analysis (Model 2) revealed that gender and discrepancy scores and also, gender and peer status, interacted in predicting peer nominations of physical aggression. To interpret the first interaction we plotted simple regression lines of overestimations of social acceptance on peer nominations of physical aggression separately for girls and boys controlling for effects of peer status. For both genders, overestimations of social acceptance significantly predicted peer nominations of physical aggression, $\beta=.28, t=3.24, p<.01$, and $\beta=.23$, $t=2.94, p<.01$ for girls and boys, respectively. Hence, in addition to boys being generally more aggressive than girls, the significant interaction effect indicated that boys who highly overestimated their social acceptance were perceived by peers as more physically aggressive than boys with low levels of overestimation, which also was the case for girls although the effect on aggression of level of discrepancy scores was less for girls. As seen in Figure 3, the slope of the regression line was steeper for boys than for girls.

To interpret the second interaction effect we plotted simple regression lines of peer status on peer nominations of physical aggression controlling for effects of overestimations of social acceptance separately for girls and boys. For boys, peer status significantly predicted ratings of physical aggression, $\beta=-.22, t=-2.80, p<.01$ whereas no effects of peer status on peer nominations of physical aggression was found for girls, $\beta=-.14, t=-1.72$, NS. Hence, as illustrated in Figure 4, rejected boys were perceived by peers as more physically aggressive than boys of average peer status whereas peer nominations of physical aggression did not differ as a function of peer status for girls. Finally, three-way interaction effects of gender, peer status, and selfesteem were not significant. 
12 Sofia Diamantopoulou, Ann-Margret Rydell and Lisbeth Henricsson



Figure 3. Illustration of Interaction Effects between Gender and Discrepancy Scores (DS) on Peer Nominations of Physical Aggression (Model 2).

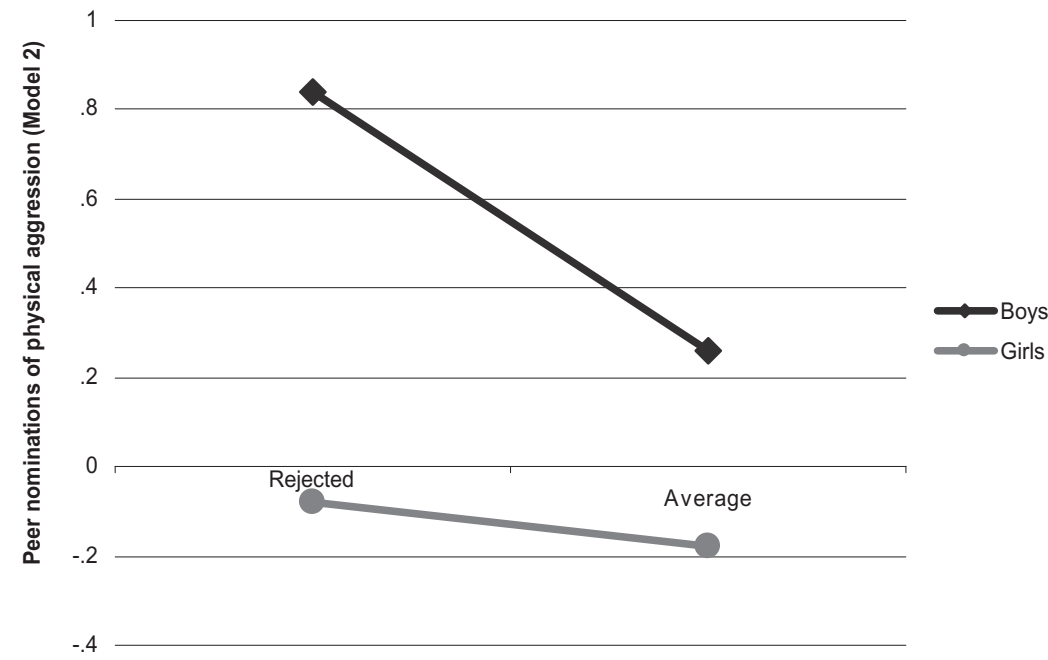

Figure 4. Illustration of Interaction Effect between Gender and Peer Status on Peer Nominations of Physical Aggression (Model 2).

\section{Discussion}

In this study, two hypotheses concerning the relations between self-esteem and aggression were examined; the low self-esteem hypothesis suggesting that low self-esteem is associated with acts of aggression and the disputed self-esteem hypothesis suggesting that aggressive behavior is related to exaggerated, in relation to observers' ratings, levels of self-esteem combined with less favorable judgments by others. Both hypotheses received support from the findings. In line with the low self-esteem hypothesis, 
low levels of global self-worth were related to high levels of aggression (i.e., both peer nominations of physical aggression and teacher ratings of aggressive behavior). In line with the disputed self-esteem hypothesis, among rejected, but not among average children, high levels of overestimations of social acceptance were related to high levels of aggression. In terms of gender differences, boys high on overestimations of social acceptance were rated by peers as being more physically aggressive than equivalent girls.

As regards low global self-worth and aggression, what the present findings add to the literature is that low levels of global self-worth did not appear to be related to aggression only as a reflection of either poor peer acceptance or of internalizing problems although both these two latter variables contributed to predicting aggression. Furthermore, the findings directly address aggression, which is also a novel finding as previous studies have investigated the broad spectrum of externalizing problems in relation to self-worth (e.g., Donnellan et al., 2005). A possible interpretation of these results could be that low global self-worth is associated with high levels of negative emotionality which in turn is related to aggression (Rydell, Berlin, \& Bohlin, 2003). However, we should note that the relations between global self-worth and peer and teacher ratings of aggression were weak and that low global self-worth played a small role in predicting aggression compared to male gender and low peer acceptance.

Although not a focus of this study, the finding that gender and peer acceptance acted as suppressors in the relation between internalizing problems and physical aggression needs some comment. The suppressor analysis provided a picture of 'pure' relations between internalizing problems and peer nominations of physical aggression when gender and peer acceptance were controlled for, indicating that aggression and internalizing problems are negatively related. In actuality, when peers rate a child's levels of physical aggression, their ratings are not free from their perceptions of the child's gender or social status. Hence, these findings should be interpreted with caution.

This study complements previous findings on the relation between disputed selfesteem and aggression. Unlike prior studies (e.g., Van Boxtel et al., 2004) we excluded children of popular, neglected, and controversial peer status from the analyses and contrasted rejected children with average children. We believe that this strategy affords a fairly robust base for conclusion as it gives a distinct picture of children with disputed vs. not disputed self-esteem - for instance, including neglected and controversial children in the comparison group could be including children with disputed self-esteem. However, as demonstrated in the regressions, overestimations of social acceptance significantly predicted aggression regardless of peer status. Previous studies have reported similar findings as exaggerated self-perceptions of one's social functioning relative to peer nominations have been associated with externalizing problems in children including physical and relational aggression, antisocial behavior, and symptoms of hyperactivity/inattention (Brendgen, Vitaro, Turgeon, Poulin, \& Wanner, 2004; David \& Kistner, 2000; Hughes, Cavell, \& Grossman, 1997; Pardini, Barry, Barth, Lochman, \& Wells, 2006). Hence, overestimations of social acceptance stood forward as a significant correlate of aggression and this effect was particularly strong for children whose rejected peer status indicated disputed self-esteem.

Why are overestimations of social acceptance linked to aggression in children? Although resolving this issue is beyond the scope of this study, one possible explanation may have to do with poor social information processing. Poor social information processing has been found to be characteristic of aggressive children (e.g., Dodge, 1993; Dodge \& Price, 1994; for a meta-analytic review, see Orobio de Castro, 
Veerman, Koops, Bosch, \& Monshouwer, 2002). Hence, aggressive children may appear to be overestimating their social acceptance due to poor ability to interpret social cues and apprehend their social standing. We suggest that future studies examine whether poor social information processing mediates the relation between overestimations of social acceptance and aggression in children.

In terms of gender differences, the relations between overestimation of social acceptance and physical aggression in the eyes of peers was particularly strong for boys. In contrast, gender did not affect the relations between global self-worth and aggression. These findings have not previously been reported in the self-esteem literature. Although David and Kistner (2000) examined interaction effects between gender and overestimations of social acceptance for both physical and relational aggression (i.e., aggression that aims to harm others' social relations) the latter considered more common among girls, they did not report any significant results. Thus, overestimations may be a particularly strong force behind boys' aggression, while low self-worth seemingly has similar effects for boys and girls. However, because little is known about gender differences in the relation between self-esteem and aggression in children, our results should be considered preliminary. Furthermore, although, as indicated by the findings of David and Kistner (2000), the inclusion of relational aggression in examinations of aggression, self-esteem, and peer rejection may not yield any significant gender differences, we suggest that future studies conduct such examinations as knowledge in this area is limited.

In the present study, we examined children's social acceptance only within the classroom. However, aggressive children have been found to affiliate with other aggressive children who do not necessarily attend the same class (Asher, Parkhurst, Hymel, \& Williams, 1990), which may explain why they appear to overestimate their social acceptance (e.g., Brendgen, Vitaro, \& Bukowski, 2000; Fergusson, SwainCampbell, \& Horwood, 2002). Because such a mechanism may be present in the relation between overestimations of social acceptance and aggression, future studies should also examine children's peer relations outside the classroom.

The findings of the present study also raise new questions. Firstly, it is clear that longitudinal studies are needed to help establish the direction of the associations between aggression and self-esteem. For instance, how does engaging in aggressive acts influence children's self-views over time and how do overestimations of competence and behavior influence children's aggressive behavior over time? Secondly, the findings of the present study demonstrated that children who overestimated their social acceptance and received feedback that was at odds with their self-views (i.e., peer rejection) were seen as particularly aggressive. As a result, future research should investigate what other possible types of discrepant feedback contribute to aggressive behavior. Further, an asset of the present study was that two aspects of self-esteem were investigated in one sample. The regression analyses, particularly the additional regression analysis that pitted low global self-worth against overestimations of social acceptance, indicated that overestimations had a larger impact on aggression than had low self-esteem but that the combination of low self-esteem and high levels of overestimations did not increase aggression. These results must be regarded as preliminary, but they point to the fruitfulness of investigating different conceptualizations of self-esteem in order to deepen the knowledge of how children's self views relate to social behavior.

In sum, overestimations of social acceptance in general, disputed self-esteem, and low global self worth were associated with high aggression levels. Hence, depending on how self-esteem is operationalized, the self-esteem of aggressive children may 
appear as both high and low. The present findings have implications regarding intervention programs for aggressive children. Insofar as positive effects of intervention studies aiming to either increase or reduce aggressive children's self-esteem to improve their social acceptance are lacking, approaches targeting self-esteem are not recommended. A more fruitful approach seems to be improving aggressive-rejected children's social skills as positive long-term effects of such interventions have been reported, including decreases in levels of aggression over time and increased peer liking (DeRosier, 2004; Fraser, Galinsky, Smokowski, Day, \& Terzian, 2005).

\section{References}

Aiken, L. S., \& West, S. G. (1991). Multiple Regression: Testing and interpreting interactions. Newbury Park, CA: Sage.

Asher, S. R., Parkhurst, J. T., Hymel, S., \& Williams, G. A. (1990). Peer rejection and loneliness in childhood. In S. R. Asher \& J. D. Coie (Eds.), Peer rejection in childhood (pp. 253-273). New York: Cambridge University Press.

Baumeister, R. F., Bushman, B. J., \& Campbell, W. K. (2000). Self-esteem, narcissism, and aggression: Does violence result from low self-esteem or from threatened egotism? Current Directions in Psychological Science, 9, 26-29.

Baumeister, R. F., Smart, L., \& Boden, J. M. (1996). Relation of threatened egotism to violence and aggression: The dark side of high self-esteem. Psychological Review, 103, 5-33.

Brendgen, M., Vitaro, F., \& Bukowski, W.-M. (2000). Deviant friends and early adolescents' emotional and behavioral adjustment. Journal of Research on Adolescence, 10, 173-189.

Brendgen, M., Vitaro, F., Turgeon, L., Poulin, F., \& Wanner, B. (2004). Is there a dark side of positive illusions? Overestimation of social competence and subsequent adjustment in aggressive and nonaggressive children. Journal of Abnormal Child Psychology, 32, 305320.

Bushman, B. J., \& Baumeister, R. F. (1998). Threatened egotism, narcissism, self-esteem, and direct and displaced aggression: Does self-love or self-hate lead to violence? Journal of Personality and Social Psychology, 75, 219-229.

Cassidy, J., \& Asher, S. R. (1992). Loneliness and peer relations in young children. Child Development, 63, 350-365.

Cohen, J., \& Cohen, P. (1983). Applied multiple regression/correlation analysis for the behavioral sciences (2nd ed.). Hillsdale, NJ: Lawrence Erlbaum Associates.

Coie, J. D., \& Dodge, K. A. (1983). Continuities and changes in children's social status: A five-year longitudinal study. Merrill-Palmer Quarterly, 29, 261-282.

Cole, D. A., Maxwell, S. E., Martin, J. M., Peeke, L. G., \& Seroczynski, A. D. (2001). The development of multiple domains of child and adolescent self-concept: A cohort sequential longitudinal design. Child Development, 72, 1723-1746.

David, C. F., \& Kistner, J. A. (2000). Do positive self-perceptions have a 'dark side'? Examination of the link between perceptual bias and aggression. Journal of Abnormal Child Psychology, 28, 327-337.

De Los Reyes, A., \& Kazdin, A. E. (2004). Measuring informant discrepancies in clinical child research. Psychological Assessment, 16, 330-334.

DeRosier, M. E. (2004). Building relationships and combating bullying: Effectiveness of a school-based social skills group intervention. Journal of Clinical Child and Adolescent Psychology, 33, 196-201.

Diamantopoulou, S., Henricsson, L., \& Rydell, A.-M. (2005). ADHD symptoms and peer relations of children in a community sample: Examining associated problems, selfperceptions, and gender differences. International Journal of Behavioral Development, 29, 388-398.

Dodge, K. A. (1993). Social-cognitive mechanisms in the development of conduct disorder and depression. Annual Review of Psychology, 44, 559-584.

Dodge, K. A., \& Price, J. M. (1994). On the relation between social information processing and socially competent behavior in early school-aged children. Child Development, 65, 13851397. 
Donnellan, M. B., Trzesniewski, K. H., Robins, R., Moffitt, T. E., \& Caspi, A. (2005). Low self-esteem is related to aggression, antisocial behavior, and delinquency. Psychological Science, 16, 328-335.

Fergusson, D. M., \& Horwood, L. J. (2002). Male and female offending trajectories. Development and Psychopathology, 14, 159-177.

Fergusson, D. M., Swain-Campbell, N. R., \& Horwood, L. J. (2002). Deviant peer affiliations, crime, and substance use: A fixed effects regression analysis. Journal of Abnormal Child Psychology, 30, 419-430.

Fraser, M. W., Galinsky, M. J., Smokowski, P. R., Day, S. H., \& Terzian, M. R. (2005). Social information-processing skills training to promote social competence and prevent aggressive behavior in the third grades. Journal of Consulting and Clinical Psychology, 73, 10451055.

Gjerde, P. F., Block, J., \& Block, J. H. (1988). Depressive symptoms and personality during late adolescence: Gender differences in the externalization-internalization of symptom expression. Journal of Abnormal Psychology, 97, 475-486.

Guerra, V. S., Asher, S. R., \& DeRosier, M. E. (2004). Effect of children's perceived rejection on physical aggression. Journal of Abnormal Child Psychology, 32, 551-563.

Harris, J. R. (1995). Where is the child's environment? A group socialization theory of development. Psychological Review, 102, 458-489.

Harter, S. (1988). Manual for the self-perception profile for adolescents. Denver, CO: University of Denver.

Harter, S. (1999). The construction of self: A developmental perspective. New York: The Guilford Press.

Henricsson, L., \& Rydell, A.-M. (2006). Children with behavior problems: The influence of social competence and social relations on problem stability, school achievement and peer acceptance across the first six years of school. Infant and Child Development, 15, 347-366.

Hughes, J. N., Cavell, T. A., \& Grossman, P. B. (1997). A positive view of self: Risk or protective factor for aggressive children? Development and Psychopathology, 9, 75-94.

Hymel, S., Bowker, A., \& Woody, E. (1993). Aggressive versus withdrawn unpopular children: Variations in peer and self-perceptions in multiple domains. Child Development, 64, 879-896.

Ladd, G. W. (1999). The pathways project cohort one. Administration guide. Tucson, AZ: University of Arizona.

Ladd, G. W., \& Troop-Gordon, W. (2003). The role of chronic peer difficulties in the development of children's psychological adjustment problems. Child Development, 74, 1344-1367.

Maughan, B., Rowe, R., Messer, J., Goodman, R., \& Meltzer, H. (2004). Conduct disorder and oppositional defiant disorder in a national sample: Developmental epidemiology. Journal of Child Psychology and Psychiatry and Allied Disciplines, 45, 609-621.

Newcomb, A. F., Bukowski, W. M., \& Pattee, L. (1993). Children's peer relations: A metaanalytic review of popular, rejected, neglected, controversial, and average sociometric status. Psychological Bulletin, 113, 99-128.

Orobio de Castro, B., Veerman, J. W., Koops, W., Bosch, J. D., \& Monshouwer, H. J. (2002). Hostile attribution of intent and aggressive behavior: A meta-analysis. Child Development, 73, 916-934.

Pardini, D. A., Barry, T. D., Barth, J. M., Lochman, J. E., \& Wells, K. C. (2006). Self-perceived social acceptance and peer social standing in children with aggressive-disruptive behaviors. Social Development, 15, 46-64.

Patterson, C. J., Kupersmidt, J. B., \& Griesler, P. C. (1990). Children's perceptions of self and relationships with others as a function of sociometric status. Child Development, 61, 13351349.

Rudolph, K. D., Caldwell, M. S., \& Conley, C. S. (2005). Need for approval and children's well-being. Child Development, 76, 309-323.

Rudolph, K. D., \& Clark, A. G. (2001). Conceptions of relationships in children with depressive and aggressive symptoms: Social-cognitive distortions or reality? Journal of Abnormal Child Psychology, 29, 41-56.

Rutter, M., Tizard, J., \& Whitmore, K. (1970). Education, health and behaviour. London: Longman Group.

Rydell, A.-M., Berlin, L., \& Bohlin, G. (2003). Emotionality, emotion regulation, and adaptation among 5- to 8-year old children. Emotion, 3, 30-47. 
Scourfield, J., John, B., Martin, N., \& McGuffin, P. (2004). The development of prosocial behaviour in children and adolescents: A twin study. Journal of Child Psychology and Psychiatry and Allied Disciplines, 45, 927-935.

Tabachnik, B. G., \& Fidell, L. S. (2001). Using multivariate statistics (4th ed.). Needham Heights, MA: Allyn \& Bacon.

Van Boxtel, H. W., Orobio de Castro, B., \& Goossens, F. A. (2004). High self-perceived social competence in rejected children is related to frequent fighting. European Journal of Developmental Psychology, 1, 205-214.

Weiss, B., \& Catron, T. (1994). Specificity of the comorbidity of aggression and depression in children. Journal of Abnormal Child Psychology, 22, 389-401.

Weiss, B., Süsser, K., \& Catron, T. (1998). Common and specific features of childhood psychopathology. Journal of Abnormal Psychology, 107, 118-127.

Wichstrøm, L. (1995). Harter's self-perception profile for adolescents: Reliability, validity, and evaluation of the question format. Journal of Personality Assessment, 65, 100-116.

Zakriski, A. L., \& Coie, J. D. (1996). A comparison of aggressive-rejected and nonaggressiverejected children's interpretations of self-directed and other-directed rejection. Child Development, 67, 1048-1070.

\section{Acknowledgments}

This study was supported by grants from the Swedish Research Council and from The Bank of Sweden Tercentenary Foundation. 